\title{
Prevalence, risk factors, and clinical manifestations of schistosomiasis among school children in the White Nile River basin, Sudan
}

\author{
Hassan Ahmed Hassan Ahmed Ismail', Sung-Tae Hong ${ }^{2}$, Azza Tag Eldin Bashir Babiker ${ }^{3}$, \\ Randa Mohamed Abd Elgadir Hassan ${ }^{4}$, Mohammed Ahmed Zakaria Sulaiman ${ }^{4}$, Hoo-Gn Jeong ${ }^{5}$, Woo-Hyun Kong ${ }^{5}$, \\ Soon-Hyung Lee ${ }^{5}$, Han-Ik Cho ${ }^{5}$, Hae-Sung Nam ${ }^{6}$, Chung Hyeon $\mathrm{Oh}^{7}$ and Young-Ha Lee ${ }^{1 *}$
}

\begin{abstract}
Background: We investigated the prevalence, risk factors, and clinical manifestations of schistosomiasis in White Nile State, Sudan, to determine the local characteristics of schistosomiasis in the White Nile River basin.

Methods: Urine and stool samples were collected from 338 students (176 boys, 162 girls) at three primary schools and were examined using the urine filtration method and the Kato-Katz technique, respectively. Of the students, 200 were interviewed using a semi-structured questionnaire to assess water-contact patterns and health conditions related with urinary schistosomiasis.
\end{abstract}

Results: Of the 338 students, egg-positive rates for S. haematobium and S. mansoni were $45.0 \%$ and $5.9 \%$, respectively, and $4.4 \%$ were mixed. The intensities of S. haematobium and S. mansoni infection were $1.091 \pm 0.744$ log EP10 (eggs per $10 \mathrm{~mL}$ of urine, mean $\pm \mathrm{SD}=57 \pm 172 \mathrm{EP} 10$ ) and $1.787 \pm 0.844 \log \mathrm{EPG}$ (eggs per gram of stool, mean $\pm \mathrm{SD}=$ $156 \pm 176 \mathrm{EPG}$ ), respectively. The prevalence and intensity of S. haematobium infection differed significantly among the three schools, but not by gender or age. Urinary schistosomiasis was significantly associated with the frequencies of contaminated water contact, taking baths, swimming, and wading the stream; however, frequencies of these events were not significantly correlated with infection intensity. Self-reported hematuria and dysuria also correlated significantly with urinary schistosomiasis.

Conclusions: The overall prevalence of schistosomiasis, especially urinary schistosomiasis, is high in the White Nile River basin, Sudan, and is closely associated with frequencies of water contact, taking baths, swimming, and wading the stream. We strongly recommend implementation of an integrated schistosomiasis control program in this area.

Keywords: Schistosoma haematobium, Schistosoma mansoni, Egg positive rate, Infection intensity, Water-contact pattern, White Nile River basin of Sudan

\section{Background}

Schistosomiasis, one of the most prevalent neglected tropical diseases (NTDs), remains as a public health problem in many developing countries in the tropics and subtropics, and 700 million people worldwide are at risk of this infection $[1,2]$. Over $90 \%$ of the disease is currently found in sub-Saharan Africa, where more than 200,000 deaths are attributed to schistosomiasis annually [3,4]. There are

\footnotetext{
* Correspondence: yhalee@cnu.ac.kr

'Departments of Infection Biology, Chungnam National University School of Medicine, Daejeon 301-131, Korea

Full list of author information is available at the end of the article
}

several examples of dramatic increases in the prevalence of schistosomiasis as a result of irrigation project construction in sub-Saharan Africa [5]. The World Health Organization (WHO) estimated that the number of countries considered as endemic for schistosomiasis was 78 in 2011, and 243 million people require preventative chemotherapy, including 111 million school-age children, of which 226 million are in Africa [3]. However, only 28 million people received treatment, which is only $10.2 \%$ coverage of the global requirement for schistosomiasis treatment [3]. 
Schistosomiasis is a parasitic disease caused by blood vessel-dwelling flukes of the genus Schistosoma. There are several species in the genus but primarily $S$. haematobium (causes urinary schistosomiasis), S. mansoni, and S. japonicum (both cause intestinal schistosomiasis) infect humans. Humans are usually infected by cercarial invasion through the skin when they come into contact with contaminated freshwater during daily life [1]. In the endemic areas, children, women, fishermen, and farmers in irrigation channels are often infected with schistosomes. Urinary schistosomiasis is characterized by hematuria as a classical sign, and is associated with bladder and urethral fibrosis and hydronephrosis that are commonly seen in chronic cases, while bladder cancer is a possible latestage complication [6]. Clinical manifestations of intestinal schistosomiasis include abdominal pain, diarrhea, and blood in the stool. In advanced cases, hepatosplenomegaly is common and is repeatedly associated with ascites and other signs of portal hypertension [1].

Sudan has wide river basin areas, due to the crossings of the Blue Nile, White Nile, and Nile Rivers, and had a large irrigated agriculture sector along the banks of these rivers. Due to this geographical environment, schistosomiasis has affected many people of Sudan for many centuries, especially in the major irrigation systems in the Gezira area between the Blue and White Nile Rivers [7,8]. To date, schistosomiasis is the most prevalent parasitic disease in Sudan, and there have been some epidemiological studies on human schistosomiasis in the Gezira Managil area, Southern Kordofan, and South Darfur, Sudan [7-14]. The White Nile River is across the White Nile State. The slow current of the White Nile River and the presence of the dense grasses and vegetation in the river create a good environment for intermediate host breeding and growth. Furthermore, there are few sanitary and clean watersupply facilities in White Nile State. It was reported that White Nile State was one of the endemic regions of schistosomiasis [8]. However, it is difficult to find recent reports, published within 10 years, about the prevalence of schistosomiasis of residents who live in White Nile River basin of White Nile State. Furthermore, there has been no reports about the risk factors for transmission of schistosomiasis in Sudan. Therefore, in order to evaluate the prevalence, risk factors for transmission, and clinical manifestations of schistosomiasis in the White Nile River basin, Sudan, we conducted urine and stool examinations as well as questionnaire surveys at three primary schools along the White Nile River basin in Sudan.

\section{Methods}

\section{Ethical statement}

This study protocol was reviewed and approved by the institutional review board of the Korea Association of Health Promotion (Acceptance No. 10-C-05) and was also approved by the National Control Program for Schistosomiasis and Soil-Transmitted Helminthes, Federal Ministry of Health, Sudan. Before doing the survey at each school, informed verbal and/or formal written consent was obtained from each child in the presence of school teachers.

\section{The surveyed areas and population}

The purpose of this survey was to evaluate the prevalence of schistosome infection among the primary school children in White Nile State. Thus, three primary schools were selected in the White Nile River basin in White Nile State, Sudan (Figure 1). The local activities of inhabitants were based on agriculture. In total 338 (176 boys, 162 girls) were enrolled from three primary schools at Khour Ajwal, Elzaefa Elahamda, and Sharrat villages (Table 1). All schools were located adjacent to the White Nile River, where the houses in the villages were built with mud bricks. Khou Ajwal and Elzaefa Elahamda schools are located within $1 \mathrm{~km}$ from the border of White Nile River, whereas Sharrat school is located about $3 \mathrm{~km}$ form the border of the River. They consisted of 47.0\% 7-9-year-olds (159 students), $33.7 \%$ 10-12-year-olds (114 students), and 19.2\% 13-15year-olds (65 students). Their mean age was 10.0 (range, 715) years old; $52.1 \%$ (176) were boys and $47.9 \%$ (162) girls.

\section{Parasitological examination}

Parasitological surveys were undertaken from April, 2009 to February, 2010. The urine and stool samples were collected and immediately transferred to the parasitological laboratory in Rabak, White Nile State, Sudan. Only one sample each of urine and stool was taken per child. We first observed whether the urine samples showed occult or gross hematuria, and then the urine samples were screened for S. haematobium eggs by a filtration method [15]. The filtration device was composed of a plastic filter holder with a nylon filter (pore size, $12.0 \mu \mathrm{m}$; Millipore, Ireland), fixed by a rubber O-ring that prevented urine from bypassing the filter. Urine $(10 \mathrm{~mL})$ was filtered forcibly through the filter membrane with a syringe. Eggs of S. haematobium were filtered and counted per $10 \mathrm{~mL}$ of urine (EP10) under a light microscope. Infection intensities were classified into two categories: light $(\mathrm{EP} 10<50)$ and heavy infection $(\mathrm{EP} 10 \geq 50)[16]$.

The collected stool samples were diagnosed parasitologically using the Kato-Katz technique [17]. The fecal materials were examined under a microscope, and counts were multiplied by 24 to provide total estimated egg counts. The infection intensity of $S$. mansoni was classified according to the number of eggs per gram of stool (EPG): light (EPG <100), moderate (100 $\leq$ EPG <400), or high $(E P G \geq 400)$ [18]. We also examined the other parasites beside schistosomes from the stool samples. 


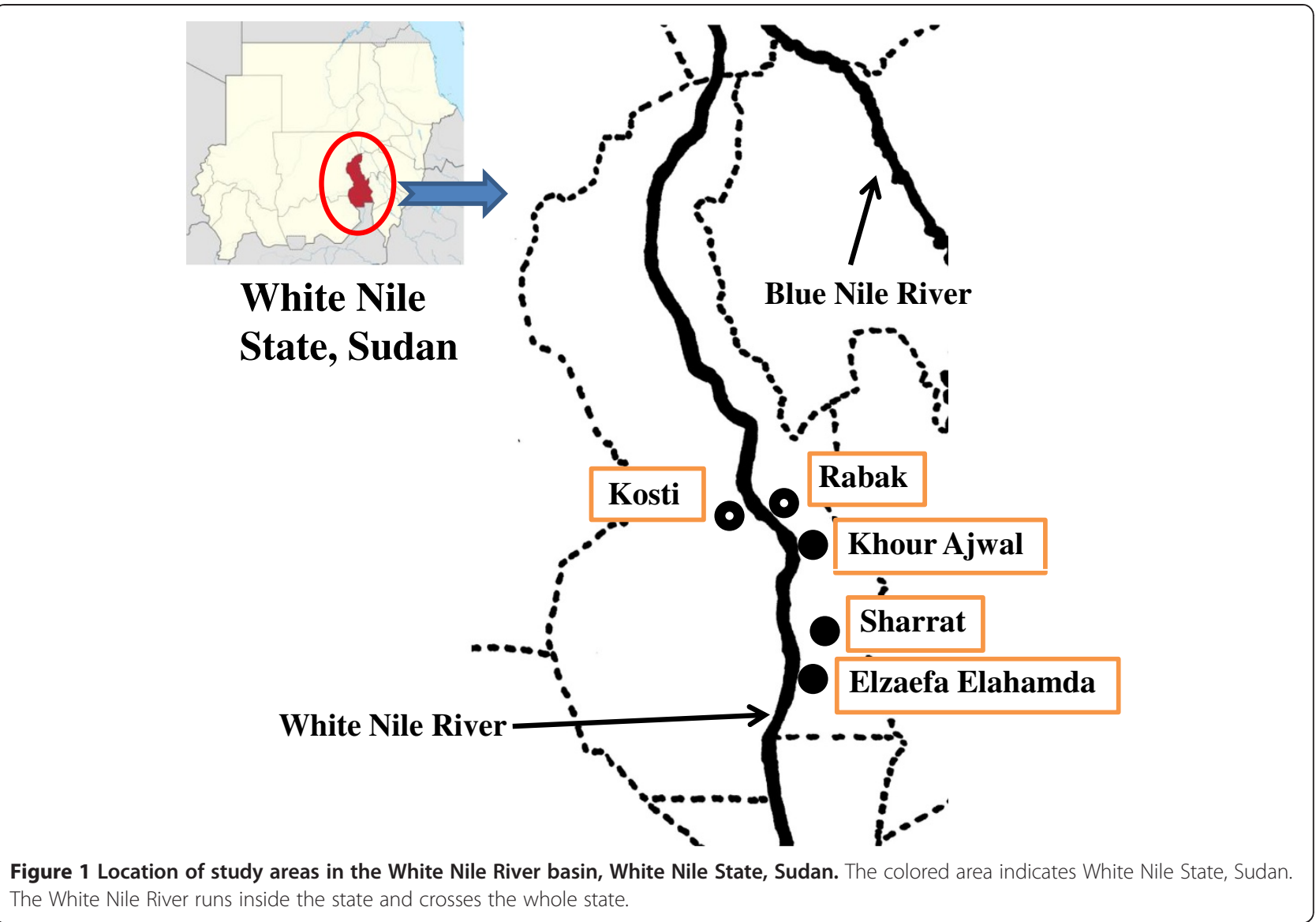

Interviews of school children on water-contact patterns and health conditions

The semi-structured questionnaires consisted of two parts: one for water-contact patterns influencing transmission of schistosomiasis, and the other for information about health conditions related to schistosomiasis. Teachers or health officials explained the process to the students thoroughly, and then the school children were interviewed individually, and their verbal responses were written down. Interviews were carried out with 125 students at Khour Ajwal school,

Table 1 Lists of surveyed schools, school children and samples for the examination of schistosomiasis in White Nile State, Sudan

\begin{tabular}{|c|c|c|c|c|c|c|c|c|c|}
\hline \multirow[t]{2}{*}{ School name } & \multirow[t]{2}{*}{ Sex } & \multirow{2}{*}{$\begin{array}{l}\text { No. of } \\
\text { exam (\%) }\end{array}$} & \multicolumn{4}{|c|}{ Age group (Years old) } & \multicolumn{3}{|c|}{ No. of samples } \\
\hline & & & $7-9$ & $10-12$ & $13-15$ & Total & Urine & Stool & Questionnaire \\
\hline \multirow[t]{3}{*}{ Khour Ajwal } & Boys & 47 & 22 & 14 & 11 & 47 & 47 & 47 & 47 \\
\hline & Girls & 78 & 28 & 28 & 22 & 78 & 78 & 78 & 78 \\
\hline & Subtotal & $125(37.0)$ & 50 & 42 & 33 & 125 & 125 & 125 & 125 \\
\hline \multirow[t]{3}{*}{ Elzaefa Elahamda } & Boys & 55 & 25 & 22 & 8 & 55 & 55 & 55 & 40 \\
\hline & Girls & 29 & 17 & 7 & 5 & 29 & 29 & 29 & 10 \\
\hline & Subtotal & $84(24.9)$ & 42 & 29 & 13 & 84 & 84 & 84 & 50 \\
\hline \multirow[t]{3}{*}{ Sharrat } & Boys & 74 & 35 & 25 & 14 & 74 & 74 & 74 & 14 \\
\hline & Girls & 55 & 32 & 18 & 5 & 55 & 55 & 55 & 11 \\
\hline & Subtotal & $129(38.2)$ & 67 & 43 & 19 & 129 & 129 & 129 & 25 \\
\hline \multirow[t]{3}{*}{ Total } & Boys & $176(52.1)$ & 82 & 61 & 33 & 176 & 176 & 176 & 101 \\
\hline & Girls & $162(47.9)$ & 77 & 53 & 32 & 162 & 162 & 162 & 99 \\
\hline & Total & $338(100.0)$ & $159(47.0)$ & $114(33.7)$ & 65 (19.2) & $338(100.0)$ & $338(100.0)$ & $338(100.0)$ & $200(59.2)$ \\
\hline
\end{tabular}


50 students at Elzaefa Elahamda school, and 25 students at Sharrat school, depending on the availability of interviewers.

\section{Statistical analyses}

Data were analyzed using the SPSS software (ver. 16.0; Chicago, IL, USA). Due to the deviation from normality distribution, infection intensity in terms of EP10 and EPG was transformed into logarithm, namely log EP10 or log EPG. The differences in continuous variables among groups were tested using a two-tailed Mann-Whitney $U$ test, Kruskal-Wallis test, and Student's $t$ test. Categorical variables were tested using the $\chi^{2}$ test. Logistic regression analysis was used to assess the association between study variables and $S$. haematobium and $S$. mansoni infection. Odds ratios (OR) and 95\% confidence intervals (CI) were calculated. Differences among groups were considered significant at $P<0.05$.

\section{Results}

\section{Overall prevalence of schistosomiasis}

As shown in Table 2 and Figure 2, 157 of 338 (46.5\%) students were found to be infected by $S$. haematobium or $S$. mansoni, and $4.4 \%$ of them had mixed infections. Seventeen children (5.0\%) from two schools (Khour Ajwal and Elzaefe Elahamda) had visible hematuria. The egg-positive rates for S. haematobium and S. mansoni were 45.0\% (152 cases) and 5.9\% (20 cases), respectively. The egg-positive rate of Schistosoma species in boys and girls were $48.9 \%$ (86 cases) and $43.8 \%$ (71 cases), respectively, and schistosome egg-positive rates were not significant differences of between sexes $(0.213<P<0.590)$. The egg-positive rates by age group were $47.8 \%$ in $7-9$-year-olds (76/159), $44.7 \%$ in 10-12-year-olds (51/114), and $46.2 \%$ in 13 -15-yearolds (30/65; Table 2). The egg-positive rates were not different between groups by age $(P>0.05)$, but did differ significantly by village: $60.0 \%$ in Khour Ajwal, $73.8 \%$ in Elzaefa Elahamda, and $14.7 \%$ in Sharrat school $(P<0.05)$. All students infected with schistosomes were treated with praziquantel at $40 \mathrm{mg} / \mathrm{kg}$. From the stool samples We also found 6 cases of Hymenolepis nana, 1 case of $H$. diminuta and 3 cases of Entamoeba coli, beside schistosome.

\section{Analysis of egg-positive cases of S. haematobium}

The egg-positive rate of S. haematobium was $45.0 \%$ (152 cases), and 15 of them were also infected with S. mansoni (double infection rate, 4.4\%; Tables 2 and 3, Figure 2). The S. haematobium egg-positive rates of boys and girls were $48.9 \%(86 / 176)$ and $40.7 \%(66 / 162 ; P=0.134)$, respectively. The egg-positive rates by age groups were $45.6 \%$ in 7-9-year-olds, $43.0 \%$ in 10-12-year-olds, and $44.6 \%$ in $13-15$-year-olds $(0.560<P<0.820)$. According to school, the egg-positive rates for S. haematobium in Khour Ajwal, Elzaefa Elahamda, and Sharrat schools were 56.8\%, 73.8\%, and $14.7 \%$, respectively $(P<0.001)$.

The intensities of S. haematobium-infected school children were $1.091 \pm 0.744 \log$ EP10 (range, 1-1,755 EP10; mean \pm SD $=57 \pm 172$ EP10; Table 3). Of these infected school children, $76.3 \%$ had light infection $(\mathrm{EP} 10<50)$ and $23.7 \%$ were considered to be heavily infected. The mean intensity in boys was $1.147 \pm 0.732 \log$ EP10 (range, 11,755 EP10) while that of girls was $1.019 \pm 0.760 \log$ EP10 (range, $1-570 \mathrm{EP10} P=0.296)$. According to age group, the highest intensity was seen in the 7-9 year age group (1.18 $\pm 0.736 \log$ EP10; range, 1-864 EP10), followed by 10-12 years and $13-15$ years $(P=0.249)$. The intensity

Table 2 Results of positive cases of Schistosoma species based on urine and stool examination according to school and sex in White Nile State, Sudan

\begin{tabular}{|c|c|c|c|c|c|c|c|c|}
\hline \multirow[t]{2}{*}{ School name } & \multirow[t]{2}{*}{ Sex } & \multirow{2}{*}{$\begin{array}{l}\text { No. of } \\
\text { exam. (\%) }\end{array}$} & \multicolumn{4}{|c|}{ Schistosoma egg positive cases by age group (\%) } & \multirow[t]{2}{*}{ OR $(95 \% \mathrm{Cl})$} & \multirow[t]{2}{*}{$P$-value } \\
\hline & & & 7-9 & $10-12$ & 13-15 & Total & & \\
\hline \multirow[t]{3}{*}{ Khour Ajwal } & Boys & 47 & 16 & 9 & 5 & 30 & $1.228(0.582-2.590)$ & 0.590 \\
\hline & Girls & 78 & 16 & 17 & 13 & 46 & 1 & \\
\hline & Subtotal & 125 & 33 & 26 & 18 & $76(60.8)$ & & \\
\hline \multirow[t]{3}{*}{ Elzaefa Elahamda } & Boys & 55 & 20 & 15 & 8 & 43 & $1.886(0.695-5.116)$ & 0.213 \\
\hline & Girls & 29 & 11 & 5 & 3 & 19 & 1 & \\
\hline & Subtotal & 84 & 31 & 20 & 11 & $62(73.8)$ & & \\
\hline \multirow[t]{3}{*}{ Sharrat } & Boys & 74 & 8 & 4 & 1 & 13 & $1.740(0.616-4.913)$ & 0.295 \\
\hline & Girls & 55 & 5 & 1 & 0 & 6 & 1 & \\
\hline & Subtotal & 129 & 13 & 5 & 1 & $19(14.7)$ & & \\
\hline \multirow[t]{3}{*}{ Total } & Boys & 176 & 44 & 28 & 14 & $86(48.9)$ & $1.225(0.798-1.880)$ & 0.354 \\
\hline & Girls & 162 & 32 & 23 & 16 & $71(43.8)$ & 1 & \\
\hline & Total & $338(100.0)$ & $76(47.8)$ & $51(44.7)$ & $30(46.2)$ & $157(46.5)$ & & \\
\hline
\end{tabular}

OR, Odds ratio.

$\mathrm{Cl}$, confidence interval. 


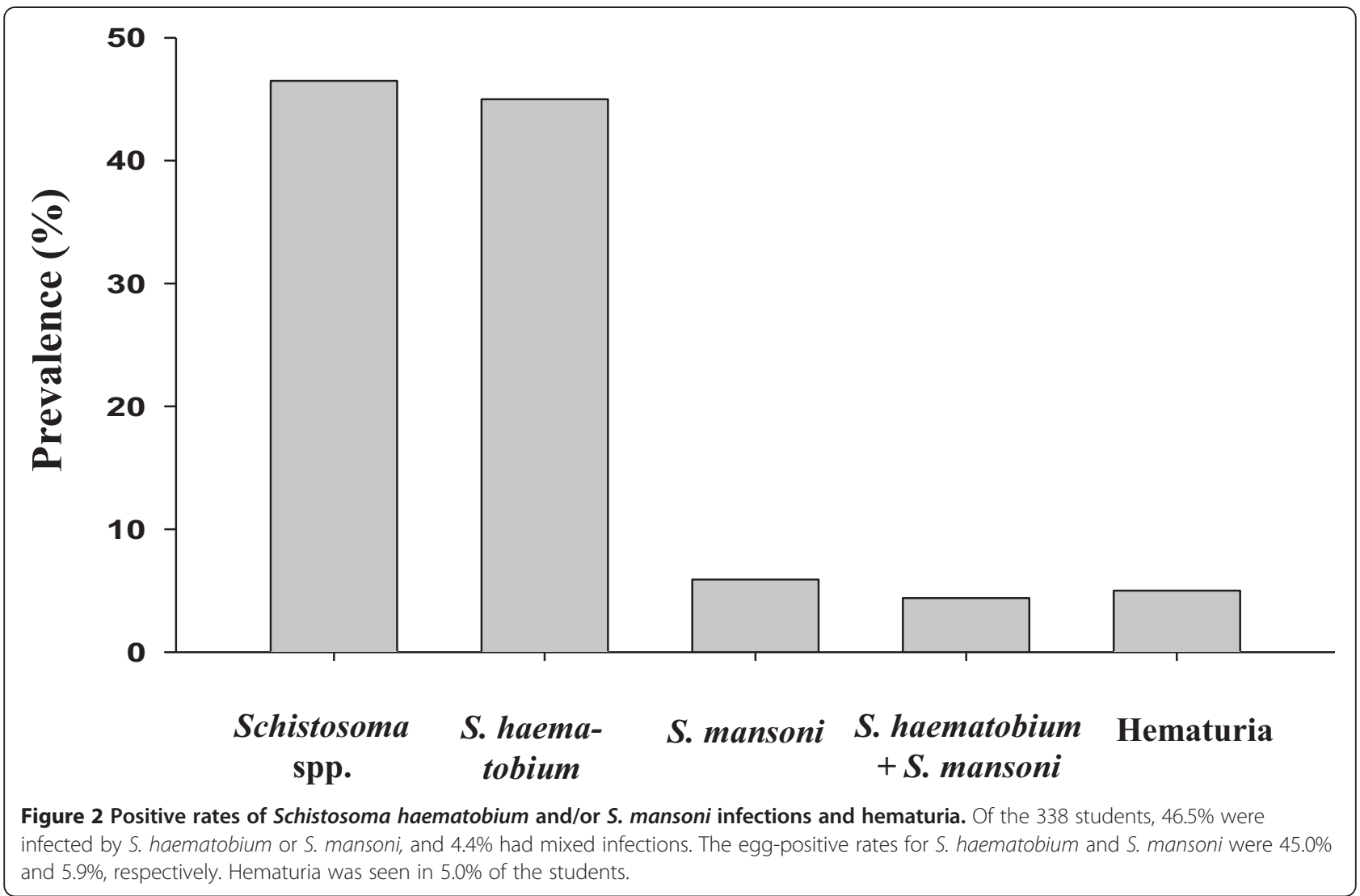

difference between schools was significant, with the highest burden of $1.355 \pm 0.634 \log$ EP10 (range, 1-864 EP10) at Elzaefa Elahamda school $(P=0.001)$.

\section{Analysis of egg-positive cases of S. mansoni}

The egg-positive rate for S. mansoni was 5.9\% (20 cases), and 15 of them were also infected with $S$. haematobium (Tables 2, 4). The $S$. mansoni egg-positive rate in girls (15 cases, 9.3\%) was higher than that in boys (5 cases,
$2.8 \% ; P=0.019)$, but the rate difference was not significant by age $(0.450<P<0.701)$. The egg-positive rate of S. mansoni was $16.0 \%$ in Khour Ajwal school, whereas none was found in the Elzaefa Elahamda or Sharrat schools (Table 4).

The intensity of $S$. mansoni-infected children was $1.787 \pm$ $0.844 \log$ EPG (range, 1-600 EPG; mean \pm SD $=156 \pm$ 176 EPG; Table 4). There was no significant difference by gender or age groups. Among infected children, $85.0 \%$

Table 3 Univariate analysis of factors associated with S. haematobium infection among school children who participated in this study $(n=338)$

\begin{tabular}{|c|c|c|c|c|c|c|c|}
\hline \multirow[t]{2}{*}{ Variable } & \multirow[t]{2}{*}{ Category } & \multirow{2}{*}{$\begin{array}{l}\text { No. } \\
\text { exam. }\end{array}$} & \multirow{2}{*}{$\begin{array}{l}\text { No. } \\
\text { positive } \\
(\%)\end{array}$} & \multirow[t]{2}{*}{ OR $(95 \% \mathrm{CI})$} & \multirow{2}{*}{$\begin{array}{l}P \text {-value } \\
\text { by logistic } \\
\text { regression }\end{array}$} & \multicolumn{2}{|c|}{ Intensity of positive cases } \\
\hline & & & & & & Mean \pm S.D. (log EP10) & $P$-value \\
\hline \multirow[t]{3}{*}{ Age in years } & $7-9$ & 159 & $74(45.6)$ & 1 & & $1.181 \pm 0.736$ & 0.249 \\
\hline & $10-12$ & 114 & $49(43.0)$ & $0.87(0.53-1.41)$ & 0.560 & $1.061 \pm 0.800$ & \\
\hline & $13-15$ & 65 & $29(44.6)$ & $0.93(0.52-1.65)$ & 0.832 & $0.914 \pm 0.654$ & \\
\hline \multirow[t]{2}{*}{ Sex } & Boys & 176 & $86(48.9)$ & 1 & & $1.147 \pm 0.732$ & 0.296 \\
\hline & Girls & 162 & $66(40.7)$ & $0.72(0.47-1.11)$ & 0.134 & $1.019 \pm 0.760$ & \\
\hline \multirow[t]{3}{*}{ School } & Khour Ajwal & 125 & $71(56.8)$ & $7.61(4.17-13.90)$ & $<0.001$ & $0.936 \pm 0.824$ & 0.001 \\
\hline & Elzaefa Elahamda & 84 & $62(73.8)$ & $16.32(8.20-32.47)$ & $<0.001$ & $1.355 \pm 0.634$ & \\
\hline & Sharrat & 129 & 19 (14.7) & 1 & & $0.810 \pm 0.483$ & \\
\hline
\end{tabular}

OR, Odds ratio.

$\mathrm{Cl}$, confidence interval. 
Table 4 Univariate analysis of factors associated with S. mansoni infection among school children who participated in this study $(\mathbf{n}=\mathbf{3 3 8})$

\begin{tabular}{|c|c|c|c|c|c|c|c|}
\hline \multirow[t]{2}{*}{ Variable } & \multirow[t]{2}{*}{ Category } & \multirow{2}{*}{$\begin{array}{l}\text { No. } \\
\text { exam. }\end{array}$} & \multirow{2}{*}{$\begin{array}{l}\text { No. } \\
\text { positive } \\
(\%)\end{array}$} & \multirow[t]{2}{*}{ OR $(95 \% \mathrm{Cl})$} & \multirow{2}{*}{$\begin{array}{l}P \text {-value } \\
\text { by logistic } \\
\text { regression }\end{array}$} & \multicolumn{2}{|l|}{ Intensity of cases } \\
\hline & & & & & & Mean \pm S.D. (log EPG) & $P$-value \\
\hline \multirow[t]{3}{*}{ Age in years } & $7-9$ & 159 & $8(5.0)$ & 1 & & $1.537 \pm 0.960$ & 0.736 \\
\hline & $10-12$ & 114 & $7(6.1)$ & $1.23(0.43-3.49)$ & 0.701 & $1.884 \pm 0.922$ & \\
\hline & $13-15$ & 65 & $5(7.7)$ & $1.56(0.49-4.97)$ & 0.450 & $2.053 \pm 0.515$ & \\
\hline \multirow[t]{2}{*}{ Sex } & Boys & 176 & $5(2.8)$ & 1 & & $1.117 \pm 1.068$ & 0.058 \\
\hline & Girls & 162 & $15(9.3)$ & $3.47(1.23-9.78)$ & 0.019 & $2.011 \pm 0.653$ & \\
\hline \multirow[t]{3}{*}{ School } & Khour Ajwal & 125 & $20(16.0)$ & - & - & $1.787 \pm 0.844$ & - \\
\hline & Elzaefa Elahamda & 84 & $0(0.0)$ & & & & \\
\hline & Sharrat & 129 & $0(0.0)$ & & & & \\
\hline
\end{tabular}

OR, Odds ratio

$\mathrm{Cl}$, confidence interval.

were classified as light or moderate infection (EPG $<400)$, and $15.0 \%$ were considered heavily infected (EPG $\geq 400$ ).

\section{Questionnaire responses for related risk factors and symptoms}

Of the 200 students interviewed, 82 were $S$. haematobium egg-negative (41.0\%) and 118 students (59.0\%) were positive (Table 5). Regarding the frequency of water-contact, most of the children contacted water outside the house daily $(74.5 \%)$, while others did so weekly $(13.0 \%)$ or less often than weekly (12.5\%). The egg-positive rates of students who contacted water increased with increased frequency of water contact $(\mathrm{OR}=3.42,95 \% \mathrm{CI}=1.41$ $8.27, P=0.006)$, but no significant difference was seen between the frequency of water contact and infection intensity.

Next, we analyzed the risk factors for urinary schistosomiasis according to the water-contact patterns of the children. The frequencies of water-contact for taking baths $(\mathrm{OR}=4.26,95 \% \mathrm{CI}=2.02-9.00, P<0.001)$, swimming $(\mathrm{OR}=4.01,95 \% \mathrm{CI}=1.98-8.11, P<0.001)$ and wading the stream $(\mathrm{OR}=2.86,95 \% \mathrm{CI}=1.50-5.45, P=0.001)$ were related to the egg-positive rates, and positive rates were significantly higher among children who contacted water of daily versus those with weekly or less often than weekly contact $(P \leq 0.001)$. In contrast, there was no significant correlation between frequency of water contact and egg-positive rates in cases of collecting water, farming, fishing, or washing vegetables. There was no significant correlation between infection intensity and frequencies of water contact $(0.157<P<0.982$; Table 5$)$.

Table 6 summarizes symptoms related to egg-positivity and infection infectivity in urinary schistosomiasis. All of 200 students interviewed complained of at least one of the symptoms within the last 6 months. Hematuria $(\mathrm{OR}=$ 5.27, 95\% CI $=2.59-10.73, P<0.001)$ and dysuria $(\mathrm{OR}=$ 3.56, $95 \%$ CI $=1.97-6.43, P<0.001)$ were significantly correlated with $S$. haematobium infection, whereas skin redness $(\mathrm{OR}=0.49,95 \% \mathrm{CI}=0.25-0.96, P=0.038)$ was significantly related with non-infection. Skin itching, frequent fatigue, urticaria, diarrhea, fever, and weight loss were not significantly associated with urinary infection $(0.058<P<0.840)$. There was a significant correlation between infection intensity and hematuria $(P=0.028)$.

\section{Discussion}

In Sudan, schistosomiasis is the most prevalent parasitic disease, and both urogenital and intestinal forms of schistosomiasis are common throughout the country with geographically varying degrees of prevalence [19]. According to previous reports on schistosomiasis, the overall prevalences of infections with $S$. mansoni, S. haematobium, or both among 6,122 children from 27 schools in the White Nile Province were 10.1\%, 21.4\%, and $4.5 \%$, respectively [8]. The prevalence of S. haematobium in the Upper Nile region and South Darfur were $73 \%$ and $56.0 \%$, respectively $[9,10]$. And the prevalence of S. haematobium in the River Nile State and Southern Kordofan State were $1.7 \%$ and $23.7 \%$, respectively; however, there was no S. mansoni infection [11,12]. These data show that there was marked geographical variation in the prevalence of Schistosoma species infection. Depending on the survey sites, there was a big variability in Schistosoma species. The egg-positive rates of $S$. haematobium, S. mansoni, and both in the White Nile River basin were $45.0 \%, 5.9 \%$, and $4.4 \%$, respectively. The prevalence of S. haematobium infection in the area was lower than that in the Upper Nile region and South Darfur, Sudan $[9,10]$. However, compared with the results of the same area in 1996 [8], the S. haematobium egg-positive rate was increased more than two times. This study proved that the prevalence of $S$. haematobium infection was maintained at a high level in White Nile State. Schistosomiasis may have been neglected simply because it is 
Table 5 Distribution of S. haematobium egg positive rates according to water-contact patterns among 200 answered-school children in White Nile State, Sudan

\begin{tabular}{|c|c|c|c|c|c|c|c|c|}
\hline \multirow[t]{2}{*}{ Variables } & \multirow[t]{2}{*}{ No. (\%) } & \multirow{2}{*}{$\begin{array}{l}\text { No. of negative } \\
\text { (\%) }(n=82)\end{array}$} & \multirow{2}{*}{$\begin{array}{l}\text { No. of positive } \\
\text { (\%) }(n=118)\end{array}$} & \multirow[t]{2}{*}{ OR } & \multirow[t]{2}{*}{$95 \% \mathrm{Cl}$} & \multirow{2}{*}{$\begin{array}{l}P \text {-value } \\
\text { by logistic } \\
\text { regression }\end{array}$} & \multicolumn{2}{|l|}{ Intensity of positive cases } \\
\hline & & & & & & & Mean \pm S.D. $(\log$ EP10) & $P$-value \\
\hline Contact for any reason & & & & & & & & 0.609 \\
\hline Daily & $149(74.5)$ & $51(34.2)$ & $98(65.8)$ & 3.42 & $1.41-8.27$ & 0.006 & $1.099 \pm 0.781$ & \\
\hline Weekly & $26(13.0)$ & $15(57.7)$ & $11(42.3)$ & 1.30 & $0.42-4.03$ & 0.645 & $1.320 \pm 0.769$ & \\
\hline$>$ Weekly & $25(12.5)$ & $16(64.0)$ & $9(36.0)$ & 1 & & & $0.995 \pm 0.871$ & \\
\hline Collecting water & & & & & & & & 0.982 \\
\hline Daily & $147(73.5)$ & $53(36.1)$ & $94(63.9)$ & 1.89 & $0.87-4.13$ & 0.109 & $1.118 \pm 0.791$ & \\
\hline Weekly & $22(11.0)$ & $13(59.1)$ & $9(40.9)$ & 0.74 & $0.25-2.23$ & 0.590 & $1.076 \pm 0.833$ & \\
\hline$>$ Weekly & $31(15.5)$ & $16(51.6)$ & $15(48.4)$ & 1 & & & $1.090 \pm 0.757$ & \\
\hline Taking baths & & & & & & & & 0.701 \\
\hline Daily & $137(68.5)$ & $46(33.6)$ & $91(66.4)$ & 4.26 & $2.02-9.00$ & 0.000 & $1.132 \pm 0.783$ & \\
\hline Weekly & $22(11.0)$ & $8(36.4)$ & $14(63.6)$ & 3.77 & $1.27-11.21$ & 0.017 & $0.945 \pm 0.696$ & \\
\hline$>$ Weekly & $41(20.5)$ & $28(68.3)$ & $13(31.7)$ & 1 & & & $1.143 \pm 0.907$ & \\
\hline Swimming & & & & & & & & 0.658 \\
\hline Daily & $132(66.0)$ & $43(32.6)$ & $89(67.4)$ & 4.01 & $1.98-8.11$ & 0.000 & $1.149 \pm 0.784$ & \\
\hline Weekly & $21(10.5)$ & $8(38.1)$ & $13(61.9)$ & 3.15 & $1.08-9.16$ & 0.035 & $0.981 \pm 0.710$ & \\
\hline$>$ Weekly & $47(23.5)$ & $31(66.0)$ & $16(34.0)$ & 1 & & & $1.008 \pm 0.863$ & \\
\hline Washing clothes & & & & & & & & 0.643 \\
\hline Daily & $124(62.0)$ & $41(33.1)$ & $83(66.9)$ & 1.94 & $0.97-3.88$ & 0.062 & $1.154 \pm 0.774$ & \\
\hline Weekly & $31(15.5)$ & $19(61.3)$ & $12(38.7)$ & 0.60 & $0.24-1.53$ & 0.288 & $0.966 \pm 0.939$ & \\
\hline > Weekly & $45(22.5)$ & $22(48.9)$ & $23(51.1)$ & 1 & & & $1.032 \pm 0.753$ & \\
\hline Wading the stream & & & & & & & & 0.307 \\
\hline Daily & $82(41.0)$ & $22(26.8)$ & $60(73.2)$ & 2.86 & $1.50-5.45$ & 0.001 & $1.194 \pm 0.825$ & \\
\hline Weekly & $32(16.0)$ & $16(50.0)$ & $16(50.0)$ & 1.05 & $0.46-2.36$ & 0.911 & $1.194 \pm 0.756$ & \\
\hline$>$ Weekly & $86(43.0)$ & $44(51.2)$ & $42(48.8)$ & 1 & & & $0.962 \pm 0.727$ & \\
\hline Farming & & & & & & & & 0.533 \\
\hline Daily & $35(17.5)$ & $11(31.4)$ & $24(68.6)$ & 1.71 & $0.76-3.81$ & 0.193 & $0.957 \pm 0.786$ & \\
\hline Weekly & $51(25.5)$ & $21(41.2)$ & $30(58.8)$ & 1.12 & $0.57-2.18$ & 0.748 & $1.189 \pm 0.786$ & \\
\hline > Weekly & $114(57.0)$ & $50(43.9)$ & $64(56.1)$ & 1 & & & $1.133 \pm 0.786$ & \\
\hline Washing the vegetables & & & & & & & & 0.668 \\
\hline Daily & $23(11.5)$ & $8(34.8)$ & $15(65.2)$ & 1.41 & $0.56-3.52$ & 0.467 & $1.031 \pm 0.852$ & \\
\hline Weekly & $30(15.0)$ & $11(36.7)$ & $19(63.3)$ & 1.30 & $0.58-2.92$ & 0.532 & $1.253 \pm 0.772$ & \\
\hline$>$ Weekly & $147(73.5)$ & $63(42.9)$ & $84(57.1)$ & 1 & & & $1.094 \pm 0.780$ & \\
\hline Fishing & & & & & & & & 0.157 \\
\hline Daily & $11(5.5)$ & $4(36.4)$ & $7(63.6)$ & 2.00 & $0.34-4.24$ & 0.778 & $0.947 \pm .0635$ & \\
\hline Weekly & $7(3.5)$ & $4(57.1)$ & $3(42.9)$ & 0.39 & $0.11-2.36$ & 0.392 & $1.943 \pm 0.393$ & \\
\hline > Weekly & $182(91.0)$ & $74(40.7)$ & $108(59.3)$ & 1 & & & $1.099 \pm 0.790$ & \\
\hline
\end{tabular}

more difficult to include chronic disability and illness into the agenda of Ministries of Health, Sudan, especially in the presence of more important diseases such as HIV/ AIDS, TB and Malaria. Even if control successes were achieved in some areas of Sudan, they could not be sustained due to lack of funding [20].
Infection intensity reflects the number of worms infecting the individual, and is a more reliable marker of treatment success, which is defined as the removal of egg-laying worms. Also infection intensity is a better indicator of morbidity than prevalence in schistosomiasis [21]. According to the previous reports in Sudan, before 
Table 6 Distribution of S. haematobium egg positive rates according to symptoms related with urinary schistosomiasis within 6 months among 200 answered-school children in White Nile State, Sudan

\begin{tabular}{|c|c|c|c|c|c|c|c|c|}
\hline \multirow[t]{2}{*}{ Symptoms } & \multirow{2}{*}{$\begin{array}{l}\text { No. of } \\
\text { answered } \\
(\%)\end{array}$} & \multirow{2}{*}{$\begin{array}{l}\text { No. of negative. } \\
\text { (\%) }(n=82)\end{array}$} & \multirow{2}{*}{$\begin{array}{l}\text { No. of positive. } \\
\text { (\%) }(n=118)\end{array}$} & \multirow[t]{2}{*}{ OR } & \multirow[t]{2}{*}{$95 \% \mathrm{Cl}$} & \multirow{2}{*}{$\begin{array}{l}P \text {-value } \\
\text { by logistic } \\
\text { regression }\end{array}$} & \multicolumn{2}{|l|}{ Intensity positive cases } \\
\hline & & & & & & & Mean \pm S.D. (log EPG) & $P$-value \\
\hline \multicolumn{9}{|l|}{ Skin itching } \\
\hline No & $89(44.5)$ & $37(41.6)$ & $52(58.4)$ & 1 & & & $1.233 \pm 0.867$ & \\
\hline Yes & $111(55.5)$ & $45(40.5)$ & $66(59.5)$ & 1.04 & $0.59-1.84$ & 0.883 & $1.016 \pm 0.703$ & 0.136 \\
\hline \multicolumn{9}{|l|}{ Skin redness } \\
\hline No & $154(77.0)$ & $57(37.0)$ & $97(63.0)$ & 1 & & & $1.151 \pm 0.791$ & \\
\hline Yes & $46(23.0)$ & $25(54.3)$ & $21(45.7)$ & 0.49 & $0.25-0.96$ & 0.038 & $0.928 \pm 0.740$ & 0.237 \\
\hline \multicolumn{9}{|c|}{ Frequent fatigue } \\
\hline No & $107(53.5)$ & $47(43.9)$ & $60(56.1)$ & 1 & & & $1.169 \pm 0.805$ & \\
\hline Yes & $93(47.5)$ & $35(37.6)$ & $58(62.4)$ & 1.30 & $0.74-2.29$ & 0.367 & $1.052 \pm 0.763$ & 0.420 \\
\hline \multicolumn{9}{|l|}{ Hematuria } \\
\hline No & $132(66.0)$ & $70(53.0)$ & $62(47.0)$ & 1 & & & $0.962 \pm 0.778$ & \\
\hline Yes & $68(34.0)$ & $12(17.6)$ & $56(82.4)$ & 5.27 & $2.59-10.73$ & 0.000 & $1.277 \pm 0.762$ & 0.028 \\
\hline \multicolumn{9}{|l|}{ Urticaria } \\
\hline No & $199(99.5)$ & $82(41.2)$ & $117(58.8)$ & 1 & & & $1.117 \pm 0.785$ & \\
\hline Yes & $1(0.5)$ & $0(0.0)$ & $1(100.0)$ & 0.00 & 0.00 & 1.000 & 0.477 & 0.419 \\
\hline \multicolumn{9}{|l|}{ Diarrhea } \\
\hline No & $137(68.5)$ & $56(40.9)$ & $81(59.1)$ & 1 & & & $1.189 \pm 0.775$ & \\
\hline Yes & $63(31.5)$ & $26(41.3)$ & 37 (58.7) & 0.98 & $0.54-1.80$ & 0.958 & $0.942 \pm 0.785$ & 0.113 \\
\hline \multicolumn{9}{|l|}{ Fever } \\
\hline No & 77 (38.5) & $31(40.3)$ & 46 (59.7) & 1 & & & $1.283 \pm 0.785$ & \\
\hline Yes & $123(61.5)$ & $51(41.5)$ & $72(58.5)$ & 0.95 & $0.53-1.70$ & 0.866 & $1.002 \pm 0.768$ & 0.058 \\
\hline \multicolumn{9}{|l|}{ Dysuria } \\
\hline No & $86(43.0)$ & $50(58.1)$ & $36(41.9)$ & 1 & & & $1.089 \pm 0.796$ & \\
\hline Yes & $114(57.0)$ & $32(28.1)$ & $82(71.9)$ & 3.56 & $1.97-6.43$ & 0.000 & $1.121 \pm 0.783$ & 0.840 \\
\hline \multicolumn{9}{|l|}{ Weight loss } \\
\hline No & $59(29.5)$ & $25(42.4)$ & $34(57.6)$ & 1 & & & $1.075 \pm 0.733$ & \\
\hline Yes & $141(70.5)$ & $57(40.4)$ & 84 (59.6) & 1.08 & $0.59-2.01$ & 0.798 & $1.126 \pm 0.807$ & 0.752 \\
\hline
\end{tabular}

praziquantel treatment, the intensities of S. haematobium were as high as 12.9 EP10 in White Nile Province [8], 25.5 EP10 at Gereida Camp in southern Darfur [13], and 87.7 EP10 (geometric mean) in Central Sudan [16]. Also, the intensities of S. mansoni were 97.7 EPG in White Nile Province [8] and 1.7 EPG (geometric mean) in the Geizira area of Central Sudan [22]. In the present study, more than $75 \%$ of the infected children were considered to have light or moderate infection of both $S$. haematobium $(\mathrm{EP} 10<50)$ and $S$. mansoni infection (EPG <400), and the mean intensities of $S$. haematobium and S. mansoni-infected children were 57 EP10 $(1.091 \pm 0.744 \log$ EP10) and 156 EPG $(1.787 \pm 0.844$ $\log$ EPG), respectively. These data indicated that the intensities of S. haematobium and S. mansoni infection in the White Nile River basin had increased in comparison with previous results from 1996 [8], which were 12.9
EP10 and 97.7 EPG, respectively. Apparently, S. haematobium egg-positive rates in Khour Ajwal and Elzaefa Elahamda school children showed very high egg-positive rates (60.8-73.8\%); thus, mass praziquantel treatment should be conducted in school-age children and high-risk groups of the population according to the WHO regulation guidelines urgently [18]. To implement the comprehensive schisotosomiasis control, besides mass therapy, the control plan should include various components such as health education, construction of a facility to supply drinking water and sanitary facilities, and vector control.

This study showed that there were significant differences in S. haematobium egg-positive rates between schools, but not between gender or age groups. In contrast, the egg-positive rates of $S$. mansoni were significantly different between boys and girls, but not among schools or age groups. Many reports showed that males 
usually have higher prevalence of schistosomiasis than females, and this was attributed to the observation that boys are more outgoing and adventurous in nature and they tend to play away from their homes more than their female counterparts [23]. These results may be due to various factors, such as proximity to the main stream, intermediate host snail distribution, environmental contamination with human excreta, human water-contact patterns and host-parasite relationships [24]. In the present study, the egg-positive rate of Sharrat village was much lower than that of Khour Ajwal and Elzaefa Elahamda villages. It may be due to several factors. Drinking water supply facilities such as artesian well and water filter systems were established in Sharrat village, but not in the other villages. Also the distance to the White Nile River of Sharrat village was 3 times longer (about $3 \mathrm{~km}$ ) than that of Khour Ajwal and Elzaefa Elahamda villages (both within $1 \mathrm{~km}$ ). Furthermore, Sharrat villagers may receive more health education about how to manage the pump operating clean water and the importance of clean water.

Schistosomiasis has been spread by contact with water that contains the larval parasites. In the present study, a higher frequency of water contact was significantly associated with higher positivity, but not with infection intensity. Similar results have been reported before: that the frequency of water-contact activities correlated with infective rates, but not with infection intensity $[12,23,25]$. The same patterns were observed in the present study. The frequency of water-contact activities of Sharrat school children was almost one third of Khour Ajwal and Elzaefa Elahamda schools, thus the egg-positive rate of Sharrat school children was significantly lower that of the other villagers. Next, we analyzed water-contact patterns to evaluate risk factors for the transmission of schistosomiasis. The frequency of water contact for bathing, swimming, and wading streams were significantly associated with the infection rate of urinary schistosomiasis, as reported by Rudge et al. [23]. However, others have described that fishing and watering vegetables were also closely associated with infection rates and the frequency of water-contact [25] and that the frequency of water-contact was not significantly associated with infection [26].

After infection by schistosomes, symptoms may develop, including fever, chills, cough, and muscle aches, within 12 months of infection. Later, without treatment, schistosomiasis can persist for years with abdominal pain, enlarged liver, blood in the stool and/or urine, and problems passing urine. Chronic infection can also lead to an increased risk of bladder cancer [1]. In this study, school children were the target subjects to be carefully looked at for evaluating the prevalence, risk factors and clinical manifestation of schistosomiasis, because schistosomiasis has detrimental effects on their growth and development, and the early diagnosis and treatment reduces the risk of severe disease and childhood disability $[2,27]$. Based on the questionnaire responses, hematuria and dysuria showed significant correlations with $S$. haematobium infection. Previous studies have shown that self-reported hematuria had the best correlation with urinary schistosomiasis in school-based control programs [23,28]; however, dysuria did not [29]. In the present study, the percentage of hematuria was significantly high at self-reporting cases (30\%) in comparison to the authors' observation (5\%). This is why the conditions of hematuria were different from the authors' own observation and selfreporting cases. We assessed hematuria immediately after collection of urine samples, whereas hematuria assessed by questionnaires was the accumulative result of recall of information over the last 6 months, which was not a real situation at that time point. Also, we observed that even uninfected children identified by microscopic examination reported schistosomiasis-related symptoms. The situation can be explained in several ways. First, self-reporting symptoms beside hematuria or dysuria were not specific for schistosomiasis, so they could suffer these symptoms arising from the other diseases during last 6 months. Second, the surveyed population were primary school children, who do not have the ability to define the various features of symptoms. Indeed, the results by questionnaire showed some bias and were different from the real features of symptoms. In case of skin redness, there were significantly unrelated to infection. This could be because there are many reasons for skin redness and it was not possible for primary school children to differentiate the etiology of the skin redness by schistosomiasis or other factors.

This study has some limitations. A single egg count used in the present study is less reliable in estimating the prevalence and infection intensities of schistosomiasis. The examination of two or more specimens per child would likely have resulted in higher estimates of total prevalence and intensity. Another limitation is the lack of information on adults, preschool children, and nonenrolled school-age children. Recent reports have suggested that adults and preschool children are at risk of schistosomiasis and can contribute to transmission [30]; thus, a population based survey is required to provide an overview of schistosomiasis in the target area.

Taken together, schistosomiasis, especially urinary schistosomiasis, is highly prevalent in the White Nile River basin of Sudan. Frequencies of water-contact by bathing, swimming, and wading the stream are risk factors for schistosomiasis in school children. Self-reported hematuria and dysuria are significantly associated with $S$. haematobium infection. These data provide essential information to facilitate targeted control measures to keep children healthy in White Nile State, Sudan. 


\section{Conclusions}

Our results showed that the prevalence of schistosomiasis is still high among school children along the White Nile River basin, Sudan, especially urinary schistosomiasis. Also, the frequencies of water contact for leisure and domestic activities are significantly associated with the prevalence of schistosomiasis. Thus, there is a need for an effective schistosomiasis control program to reduce contaminated water contact through the provision of sanitary and safe-water supply facilities as well as mass chemotherapy and health education.

\section{Abbreviations}

EP10: Number of S. haematobium eggs per $10 \mathrm{~mL}$ of urine (EP10); EPG: Number of S. mansoni egs per gram of stool (EPG).

\section{Competing interests}

The authors have declared that no competing interests exist.

\section{Authors' contributions}

$\mathrm{YHL}, \mathrm{HAHAl}$ and STH designed the study, with support from $\mathrm{HGJ}$ and $\mathrm{CHO}$. ATEBB, RMAEH, MAZS and WHK coordinated the data collection and SHL and $\mathrm{HIC}$ provided parasitological expertise. HSN conducted the data analysis. YHL and STH wrote the first draft. All authors read and approved the final version of the manuscript.

\section{Acknowledgement}

This study was done as the preliminary investigation for "The Project for combating schistosomiasis in Sudan during 2009 through 2011" by Korea International Cooperation Agency (KOICA). We are indebted to several colleagues at Ministry of Health of Sudan and Embassy of the Republic of Korea in Sudan.

\section{Author details}

'Departments of Infection Biology, Chungnam National University School of Medicine, Daejeon 301-131, Korea. ${ }^{2}$ Department of Parasitology and Tropical Medicine, Seoul National University College of Medicine, Seoul 110-799, Korea. ${ }^{3}$ Schistosomiasis, Lymphatic Filariasis \& Sleeping Sickness Control Program, Federal Ministry of Health, Khartoum, Sudan. ${ }^{4}$ Schistosomiasis Research Laboratory, Department of Zoology, Faculty of Science, University of Khartoum, Khartoum, Sudan. ${ }^{5}$ Korea Association of Health Promotion (KAHP), Seoul 157-705, Korea. 'Department of Preventive Medicine, Chungnam National University School of Medicine, Daejeon 301-131, Korea. ${ }^{7}$ Korea International Cooperation Agency (KOICA), Soengnam 461-833, Korea.

Received: 29 April 2014 Accepted: 5 October 2014

Published online: 15 October 2014

\section{References}

1. Gryseels B: Schistosomiasis. Infect Dis Clin North Am 2012, 26:383-397.

2. Bruun B, Aagaard-Hansen J: The Social Context Of Schistosomiasis And Its Control. In Geneva: World Health Organization; 2008:2

3. WHO: Schistosomiasis : number of people treated in 2011. Wkly Epidemiol $\operatorname{Rec} 2013,88: 81-88$.

4. Sady H, Al-Mekhlafi HM, Mahdy MA, Lim YA, Mahmud R, Surin J: Prevalence and associated factors of schistosomiasis among children in Yemen: implications for an effective control programme. PLoS Negl Trop Dis 2013, 7:e2377.

5. Steinmann P, Keiser J, Bos R, Tanner M, Utzinger J: Schistosomiasis and water resources development: systematic review, meta-analysis, and estimates of people at risk. Lancet Infect Dis 2006, 6:411-425.

6. WhO: The control of schistosomiasis. Second report of the WHO Expert Committee. World Health Organ Tech Rep Ser 1993, 830:1-86.

7. El Gaddal AA: The Blue Nile Health Project: a comprehensive approach to the prevention and control of water associated diseases in irrigated schemes of the Sudan. J Trop Med Hyg 1985, 88:47-56.

8. Ahmed ES, Daffalla A, Christensen NO, Madsen H: Patterns of infection and transmission of human schistosomiasis mansoni and schistosomiasis haematobium in White Nile Province, Sudan. Ann Trop Med Parasitol 1996, 90:173-180.

9. Deganello R, Cruciani M, Beltramello C, Duncan O, Oyugi V, Montresor A: Schistosoma hematobium and S. mansoni among children, Southern Sudan. Emerg Infect Dis 2007, 13:1504-1506.

10. Deribe K, Eldaw A, Hadziabduli S, Kailie E, Omer MD, Mohammed AE, Jamshed T, Mohammed EA, Mergani A, Ali GA, Babikir K, Adem A, Hashim F: High prevalence of urinary schistosomiasis in two communities in South Darfur: implication for interventions. Parasit Vectors 2011, 4:14.

11. Elmadhoun WM, Msmar AH, Elnoby OA, Noor SK, Suliman AA, Bushara SO: Situation analysis of schistosomiasis and soil-transmitted helminthes in River Nile State, Sudan. Trans Roy Soc Trop Med Hyg 2013, 107:195-199.

12. Abou-Zeid AH, Abkar TA, Mohamed RO: Schistosomiasis infection among primary school students in a war zone, Southern Kordofan State, Sudan: a cross-sectional study. BMC Public Health 2013, 13:643.

13. Ahmed AA, Afifi AA, Adam I: High prevalence of Schistosoma haematobium infection in Gereida Camp, in southern Darfur, Sudan. Ann Trop Med Parasitol 2009, 103:741-743.

14. Abou-Zeid AH, Abkar TA, Mohamed RO: Schistosomiasis and soiltransmitted helminths among an adult population in a war affected area, Southern Kordofan state, Sudan. Parasit Vectors 2012, 5:133

15. Kahama Al, Odek AE, Kihara RW, Vennervald BJ, Kombe Y, Nkulila T, Hatz CF, Ouma $J$ H, Deelder AM: Urine circulating soluble egg antigen in relation to egg counts, haematuria, and urinary tract pathology before and after treatment in children infected with Schistosoma haematobium in Kenya. Am J Trop Med Hyg 1999, 61:215-219.

16. Ahmed AM, Abbas H, Mansour FA, Gasim Gl, Adam I: Schistosoma haematobium infections among schoolchildren in central Sudan one year after treatment with praziquantel. Parasit Vectors 2012, 5:108.

17. Teesdale $\mathrm{CH}$, Amin MA: A simple thick-smear technique for the diagnosis of Schistosoma mansoni infection. Bull World Health Organ 1976, 54:703-705.

18. WHO: Prevention and control of schistosomiasis and soil-transmitted helminthiasis. World Health Organ Tech Rep Ser 2002, 912:1-57.

19. WHO: Country Cooperation Strategy for WHO and Sudan 2008-2013. In EM/ARD/032/E. 2009. Available from http://www.who.int/countryfocus/ cooperation_strategy/listofccs/en/index.html [accessed on 26 December 2013].

20. Amin MA, Elhussin DM: Challenges in prevention and control of schistosomiasis in the Sudan. Sudan J Med Sci 2009, 4:79-83.

21. Davis A: Clinical trials in parasitic diseases. Trans R Soc Trop Med Hyg 2004, 98:139-141.

22. Eltayeb NM, Mukhtar MM, Mohamed AB: Epidemiology of schistosomiasis in Gezira area Central Sudan and analysis of cytokine profiles. Asian Pac J Trop Med 2013, 6:119-125.

23. Rudge JW, Stothard JR, Basáñez MG, Mgeni AF, Khamis IS, Khamis AN, Rollinson D: Micro-epidemiology of urinary schistosomiasis in Zanzibar: local risk factors associated with distribution of infections among schoolchildren and relevance for control. Acta Trop 2008, 105:45-54.

24. Mazigo HD, Nuwaha F, Kinung'hi SM, Morona D, Pinot de Moira A, Wilson S, Heukelbach J, Dunne DW: Epidemiology and control of human schistosomiasis in Tanzania. Parasit Vectors 2012, 5:274

25. Massara CL, Peixoto SV, Barros Hda S, Enk MJ, Cavalho Odos S, Schall V Factros accociated with schistosomiasis mansoni in a population from the municipality of Jaboticatubas, State of Minas Gerais, Brazil. Mem Inst Oswaldo Cruz Rio de Janeiro 2004, 99(Suppl. 1):127-134.

26. Lengeler C, Makwala J, Ngimbi D, Utzinger J: Simple school questionnaires can map both Schistosoma mansoni and Schistosoma haematobium in the Democratic Republic of Congo. Acta Trop 2000, 74:77-87.

27. Stothard JR, Sousa-Figueiredo JC, Betson M, Bustinduy A, Reinhard-Rupp J: Schistosomiasis in African infants and preschool children: let them now be treated. Trends Parasitol 2013, 29:197-205.

28. Fatiregun AA, Osungbade KO, Olumide AE: Cost-effectiveness of screening methods for urinary schistosomiasis in a school-based control programme in Ibadan, Nigeria. Health Policy 2009, 89:72-77.

29. Kapito-Tembo AP, Mwapasa V, Meshnick SR, Samanyika Y, Banda D, Bowie C, Radke S: Prevalence distribution and risk factors for Schistosoma 
hematobium infection among school children in Blantyre, Malawi.

PloS Negl Trop Dis 2009, 3:e361.

30. Njenga SM, Mwandawiro CS, Muniu E, Mwanje MT, Haji FM, Bockarie MJ:

Adult population as potential reservoir of NTD infections in rural villages

of Kwale district, Coastal Kenya: implications for preventive

chemotherapy interventions policy. Parasit Vectors 2011, 4:175.

doi:10.1186/s13071-014-0478-6

Cite this article as: Ismail et al:: Prevalence, risk factors, and clinical

manifestations of schistosomiasis among school children in the White

Nile River basin, Sudan. Parasites \& Vectors 2014 7:478.

\section{Submit your next manuscript to BioMed Central and take full advantage of:}

- Convenient online submission

- Thorough peer review

- No space constraints or color figure charges

- Immediate publication on acceptance

- Inclusion in PubMed, CAS, Scopus and Google Scholar

- Research which is freely available for redistribution 